\title{
Comparing antibiotic consumption between two European countries: are packages an adequate surrogate for prescriptions?
}

Laurence Watier ${ }^{1}$, Philippe Cavalié ${ }^{2}$, Bruno Coignard ${ }^{3}$, Christian Brun-Buisson ${ }^{1,4}$

1. Biostatistics, Biomathematics, Pharmacoepidemiology and Infectious Diseases (B2PHI), Inserm, UVSQ, Institut Pasteur, Université Paris-Saclay, Paris, France

2. Agence Nationale de Sécurité du Médicament (ANSM), Surveillance Division, Saint Denis, France

3. Santé Publique France, Saint-Maurice, France

4. Ministère de la Santé, Paris, France

Correspondence: Laurence Watier(laurence.watier@inserm.fr)

Citation style for this article:

Watier Laurence, Cavalié Philippe, Coignard Bruno, Brun-Buisson Christian. Comparing antibiotic consumption between two European countries: are packages an adequate surrogate for prescriptions?. Euro Surveill. 2017;22(46):pii=17-00352. https://doi.org/10.2807/1560-7917.ES.2017.22.46.17-00352

Article submitted on 01 Jun 2017 / accepted on 12 Oct 2017 / published on 16 Nov 2017

Defined daily doses (DDD) are the gold standard indicator for quantifying prescriptions. Since 2014, the European Centre for Disease Prevention and Control (ECDC) has also been using the number of packages per 1,000 inhabitants per day (ipd), as a surrogate for prescriptions, to report antibiotic consumption in the community and to perform comparisons between European Union (EU) countries participating in the European Surveillance of Antimicrobial Consumption Network (ESAC-Net). In 2015, consumption was reported to range across Europe from 1.0 to 4.7 packages per 1,000 ipd. Our analysis showed that consumption of antibiotics for systemic use per 1,000 ipd was on average 1.3 times greater in France than in Belgium when considering prescriptions in the numerator, 2.5 times greater when considering packages and 1.2 times greater when considering DDD. As long as the same metrics are used over time, antibiotic consumption data aggregated and disseminated by ECDC are useful for assessing temporal trends at the European level and within individual countries; these data may also be used for benchmarking across EU countries. While DDD - although imperfect - are the most widely accepted metric for this purpose, antibiotic packages do not appear suitable for comparisons between countries and may be misleading.

\section{Background}

In order to compute the overall exposure of the population to antimicrobial drugs and compare drug consumption within Europe, countries participating in the European Surveillance of Antimicrobial Consumption Network (ESAC-Net) report each year to the European Centre for Disease Prevention and Control (ECDC) the number of defined daily doses (DDD). The DDD is a widely used metric defined by the World Health Organization (WHO) [1], used for all active substances according to the anatomical therapeutic chemical (ATC) classification. These metrics are mainly based on sales or, to a lesser extent, on reimbursement data for active substances. The data include antibacterial drugs for systemic use (J01), antimycotic drugs for systemic use (Jo2), antibiotic drugs used for treatment of tuberculosis (Jo4B) and antiviral drugs for systemic use (J05). The ratio of DDD per 1,000 inhabitants and per day (ipd) is the most widely accepted indicator for comparing antibiotic consumption between countries. The ECDC has been using this indicator for reporting and comparing antibiotic consumptions within and between European Union (EU) countries participating in ESAC-Net (formerly ESAC) since 2001, with retrospective data going back to 1997.

Since 2014 , summaries disseminated by the ECDC have also reported the number of orally administered packages (OAP) per 1,000 ipd in the community for the substances classified as antibacterial drugs for systemic use (J01). This additional indicator is described as "the best available surrogate for prescriptions" when the latter are unavailable [2-4] and its purpose is to help understand changes in antibiotic consumption [5]. Antibiotic prescriptions are obtained from individual reimbursement data for ambulatory care recorded in national health insurance (NHI) databases $[6,7]$. However, the validity of this indicator is mainly related to the $\mathrm{NHI}$ coverage rate and also affected by the possibility to purchase antibiotics without a prescription. Thus, a surrogate for prescriptions derived from sales data (e.g. packages sold) could be useful. ESACNet summaries use OAP per 1,000 ipd to compare EU countries; however, this results in unexpected marked differences depending on whether the ranking of countries is based on DDD or OAP, although the reader is warned that such differences could "probably reflect 


\section{FIGURE}

Outpatient antibiotic use per year expressed as number of orally administered packages, prescriptions and defined daily doses per 1,000 inhabitants per day, France, 2006-2015 ( $\mathrm{n}=535,696,881$ prescriptions)

A. Antibiotics for systemic use (J01)

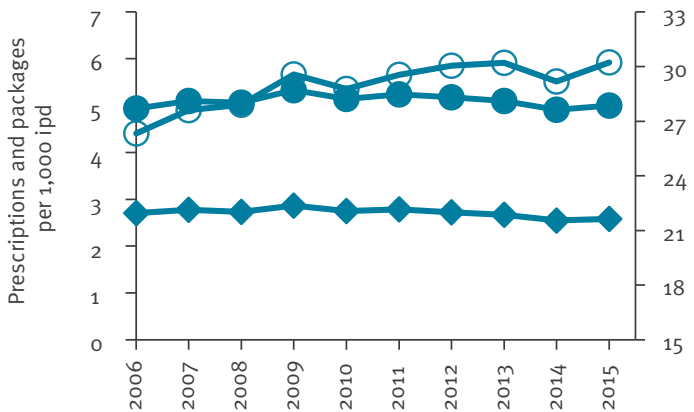

C. Other beta-lactams (Jo1D

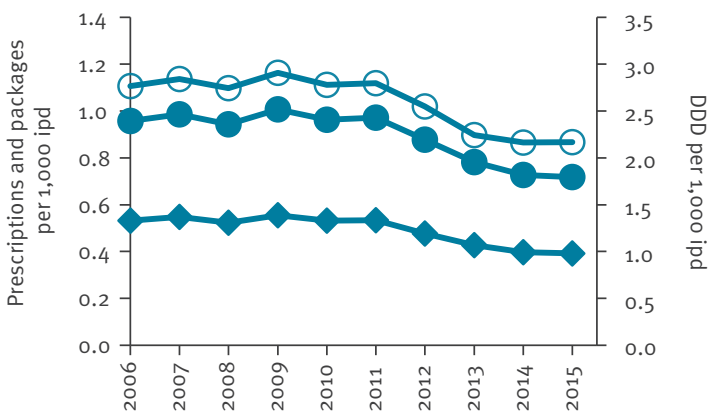

E. Macrolides, lincosamides and streptograms (J01F)

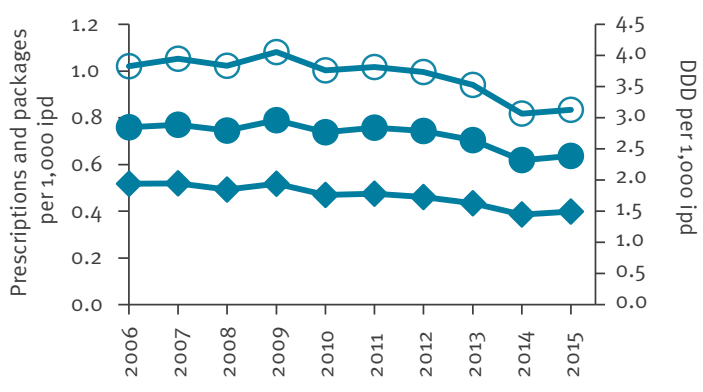

G. Sulfonamides and trimethoprim (J01E)

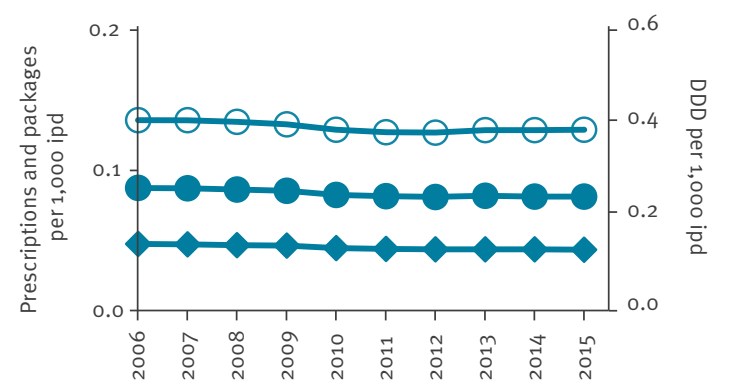

B. Penicillins (J01C)

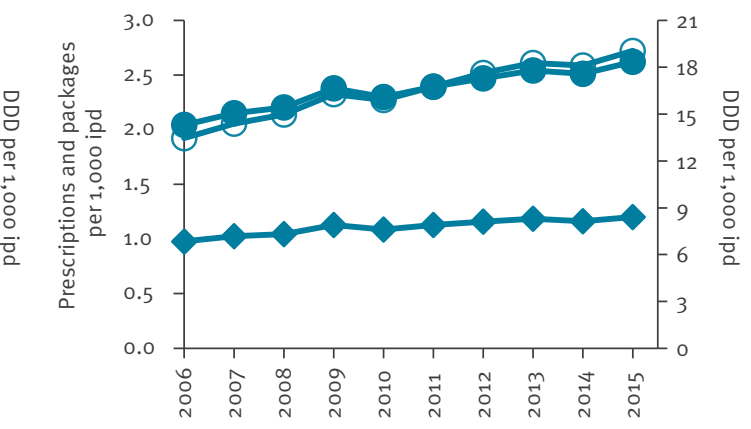

D. Tetracyclines (Jo1A)

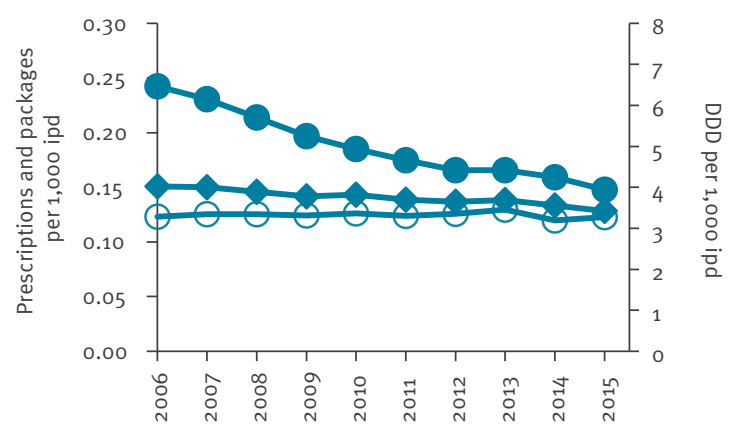

F. Macrolides (J01M)

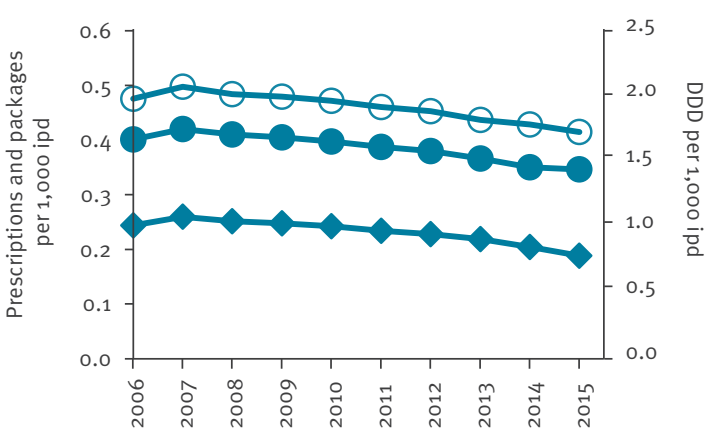

DDD: defined daily doses; ipd: inhabitants per day.

Circles: administered packages; diamonds: prescriptions; blank circles: DDD. 
TABLE 1

Number of defined daily doses, packages (all administered) and outpatient prescriptions per 1,000 inhabitants and per day, Belgium ( $n=24,690,829$ prescriptions) and France $n=161,107,123), 2006-2009$

\begin{tabular}{|c|c|c|c|c|c|c|c|c|c|}
\hline \multirow{2}{*}{ Period } & \multicolumn{3}{|c|}{ Defined daily doses } & \multicolumn{3}{|c|}{ Packages } & \multicolumn{3}{|c|}{ Prescriptions } \\
\hline & $2006-07$ & $2007-08$ & 2008-09 & $2006-07$ & $2007-08$ & 2008-09 & $2006-07$ & $2007-08$ & 2008-09 \\
\hline \multicolumn{10}{|c|}{ Belgium } \\
\hline J01 & 23.33 & 24.85 & $24 \cdot 52$ & 2.25 & 2.30 & 2.24 & 2.11 & 2.16 & 2.10 \\
\hline J01A & 1.82 & 1.95 & 1.91 & 0.13 & 0.13 & 0.13 & 0.12 & 0.12 & 0.12 \\
\hline Jo1C & 12.22 & 13.70 & 13.65 & 1.08 & 1.15 & 1.12 & 1.02 & 1.09 & 1.07 \\
\hline Jo1D & 2.30 & 2.07 & 1.70 & 0.20 & 0.16 & 0.13 & 0.19 & 0.15 & 0.12 \\
\hline Jo1E & 0.34 & 0.36 & 0.33 & 0.05 & 0.05 & 0.04 & 0.04 & 0.05 & 0.04 \\
\hline J01F & 2.39 & 2.51 & 2.54 & 0.34 & 0.35 & 0.34 & 0.32 & 0.33 & 0.32 \\
\hline J01M & 2.19 & 2.10 & 2.23 & 0.27 & 0.26 & 0.27 & 0.26 & 0.25 & 0.26 \\
\hline \multicolumn{10}{|l|}{ France } \\
\hline J01 & 26.83 & 27.74 & 28.70 & 5.44 & $5 \cdot 54$ & 5.66 & 2.72 & 2.75 & 2.80 \\
\hline J01A & 3.34 & 3.34 & 3.32 & 0.24 & 0.22 & 0.20 & 0.15 & 0.15 & 0.14 \\
\hline J01C & 13.81 & 14.68 & 15.61 & 2.12 & 2.21 & 2.33 & 0.99 & 1.03 & 1.09 \\
\hline J01D & 2.78 & 2.78 & 2.83 & 1.15 & 1.16 & 1.18 & 0.54 & 0.53 & 0.54 \\
\hline J01E & 0.41 & 0.40 & 0.40 & 0.09 & 0.09 & 0.09 & 0.05 & 0.05 & 0.05 \\
\hline J01F & 3.84 & 3.90 & 3.94 & 0.76 & 0.76 & 0.77 & 0.51 & 0.51 & 0.50 \\
\hline J01M & 2.06 & 2.04 & 2.01 & 0.42 & 0.41 & 0.41 & 0.26 & 0.26 & 0.25 \\
\hline
\end{tabular}

differences in the number of items or dose per item of antibiotics in antibiotic packages" [3,4].

To investigate the validity of OAP, we first compared the two indicators in France during the period from 2006 to 2015 . Secondly, since prescription data were publicly available only from Belgium among the countries participating into ESAC-Net [8], reasons for discrepancies in the results of ranking schemes using DDD and OAP in France and in Belgium were investigated for the period from 2006 to 2009.

\section{Comparison of defined daily doses, prescriptions and packages of antibiotic drugs delivered in France, 2006 to 2015}

We used anonymous individual data from the main general scheme of the French $\mathrm{NHI}$ agency which insures salaried workers and covered a constant proportion of around $86 \%$ of the French population during the study period. These data comprised all prescriptions and antibiotics prescribed to outpatients, dispensed by outpatient pharmacies, and reimbursed by the $\mathrm{NHI}$ from 2006 to 2015 (Commission nationale informatique et libertés (CNIL) approval DE-2015-190). To take into account French population growth during the study period, we obtained demographic data from the French National Institute for Statistics and Economic Studies [9]. Prescription data recorded in number of OAP were converted into number of DDD, according to the official DDD published by the WHO for each substance and using the rules established by the WHO to determine the appropriate DDD for combined drugs formulations. The annual number of prescriptions, OAP and DDD prescribed in France per 1,000 ipd were aggregated at the active substance level, i.e. the fifth level. The contents of oral formulations were obtained from the French public database of medicines [10]. All data were extrapolated to $100 \%$ of the French population, assuming that the $14 \%$ population not covered by the data collection had an antibiotic consumption similar to the $86 \%$ covered.

The study targeted oral antibiotics for systemic use (ATC code J01) in the community only. As in ESAC-Net summaries, antibiotics were divided in six main categories according to the ATC level 3 classification: penicillins (Jo1C), cephalosporins and other beta-lactams (Jo1D), macrolides, lincosamides and streptogramins (Jo1F), tetracyclines (J01A), quinolones (J01M) and sulfonamides and trimethoprim (Jo1E). The other classes accounted for a very small part of overall antibiotic consumption in the community and were thus omitted from the analysis.

\section{Outpatient antibiotic use in France, 2006 to 2015}

Over the 10-year study period, an average of 2.71 (range: 2.55-2.87) prescriptions, 5.10 (range: $4.91-5.33$ ) OAP and 28.94 (range: $26.33-30.22$ ) DDD per 1,000 ipd were recorded for oral antibiotics for systemic use, indicating that ca 1.9 OAP were delivered for each prescription. The number of prescriptions, OAP and DDD per 1,000 ipd varied by ATC class (Figure). The temporal trends using OAP or DDD were quite similar, except for tetracyclines for which a noticeable decrease in OAP was observed because the package size increased during the study period, with ca 1.6 and 1.1 OAP delivered for each prescription of tetracyclines in 2006 and 
TABLE 2

Content of oral amoxicillin formulations available in Belgium and in France

\begin{tabular}{|c|c|c|c|c|c|}
\hline \multirow{2}{*}{ Brand name } & \multirow{2}{*}{ Dosage } & \multicolumn{2}{|c|}{ Belgium } & \multicolumn{2}{|c|}{ France } \\
\hline & & Quantity & Active substance & Quantity & Active substance \\
\hline \multicolumn{6}{|l|}{ Brand A } \\
\hline Capsule & $500 \mathrm{mg}$ & 16 or 30 & 8 or $15 \mathrm{~g}$ & 12 & $6 \mathrm{~g}$ \\
\hline Powder for oral suspension & $250 \mathrm{mg} / 5 \mathrm{~mL}$ & $100 \mathrm{~mL}$ & $5 \mathrm{~g}$ & $60 \mathrm{~mL}$ & $3 g$ \\
\hline Powder for oral suspension & $500 \mathrm{mg} / 5 \mathrm{~mL}$ & $100 \mathrm{~mL}$ & $10 \mathrm{~g}$ & $60 \mathrm{~mL}$ & $6 \mathrm{~g}$ \\
\hline \multicolumn{6}{|l|}{ Brand B } \\
\hline Capsule & $500 \mathrm{mg}$ & 16 & $8 \mathrm{~g}$ & 12 & $6 \mathrm{~g}$ \\
\hline Dispersible tablet & $1 \mathrm{~g}$ & 8 or 20 or 24 & 8 or 20 or $24 \mathrm{~g}$ & 6 or 14 & 6 or $14 \mathrm{~g}$ \\
\hline Powder for oral suspension & $250 \mathrm{mg} / 5 \mathrm{~mL}$ & $100 \mathrm{~mL}$ & $5 \mathrm{~g}$ & $60 \mathrm{~mL}$ & $3 \mathrm{~g}$ \\
\hline Powder for oral suspension & $500 \mathrm{mg} / 5 \mathrm{~mL}$ & $100 \mathrm{~mL}$ & $10 \mathrm{~g}$ & $60 \mathrm{~mL}$ & $6 \mathrm{~g}$ \\
\hline \multicolumn{6}{|l|}{ Brand C } \\
\hline Capsule & $500 \mathrm{mg}$ & 16 & $8 \mathrm{~g}$ & 12 & $6 \mathrm{~g}$ \\
\hline Dispersible tablet & $1 \mathrm{~g}$ & 8 or 24 & 8 or $24 \mathrm{~g}$ & 6 or 14 & 6 or $14 \mathrm{~g}$ \\
\hline Powder for oral suspension & $125 \mathrm{mg} / 5 \mathrm{~mL}$ & $80 \mathrm{~mL}$ & $2 \mathrm{~g}$ & $60 \mathrm{~mL}$ & $1.5 \mathrm{~g}$ \\
\hline Powder for oral suspension & $250 \mathrm{mg} / 5 \mathrm{~mL}$ & $80 \mathrm{~mL}$ & $4 \mathrm{~g}$ & $60 \mathrm{~mL}$ & $3 \mathrm{~g}$ \\
\hline
\end{tabular}

Formulations in France and Belgium as per [10,11]. Prescribed daily doses (PDD) could not be assessed from available Belgian data.

2015, respectively. For penicillins, the temporal trends of OAP and DDD were similar but increased more than the prescriptions.

\section{Comparison of France and Belgium, 2006 to 2009}

We compared French data to those recorded in Belgium, the only other EU country from which corresponding data were publicly available for the period from 2006 to 2009. These data were retrieved from the supplementary material of the paper by Coenen et al. [8]. Three 12 -month periods from July 2006 to June 2009 could thus be compared. The contents of oral formulations were obtained from the Belgian Centre for Pharmacotherapeutic Information (CBIP) [11].

Over the 3-year study period, the numbers of packages and prescriptions in Belgium were comparable for all ATC classes considered (Table 1). In contrast, the number of packages in France was about twice as high as the number of prescriptions for ATC J01, with the packages: prescriptions ratio varying from 1.5 to 2.2 depending on the ATC class.

Compared with Belgium, consumption of antibiotics for systemic use (J01) per 1,000 ipd was on average greater in France for the three indicators: 1.3 times greater when considering prescriptions in the numerator, 2.5 times greater when considering packages and 1.2 times greater when considering DDD.

Variations were also observed according to ATC class. For penicillins, the number of prescriptions and DDD (measured per 1,000 ipd) were similar in France and Belgium, while the number of packages was twice greater in France than in Belgium. Accordingly, the quantity of active substance per package was about half in the French packages compared with Belgium. Table 2 provides examples of package contents for various amoxicillin formulations used in Belgium and in France and confirms that packages available in Belgium contain more active substance. Regarding the trends for penicillins ( $\mathrm{JO}_{1 \mathrm{C}}$ ) use in France, the discrepancy between amoxicillin prescriptions and DDD could be partly explained by the low DDD ascribed to this drug $(1 \mathrm{~g})$, which is much lower than daily doses of amoxicillin recommended in French and Belgian guidelines for lower respiratory tract infections in adults ( $3 \mathrm{~g} /$ day) $[12,13]$.

\section{Discussion}

Our analysis comparing trends in the consumption of antibiotic packages and of DDD in France shows that using antibiotic packages as a metric could be misleading. In addition, comparing antibiotic consumption across EU countries using aggregated packages may also lead to erroneous conclusions in terms of antibiotic exposure of the population, unless package contents are similar.

As long as the same metrics are used over time, antibiotic consumption data aggregated and disseminated by ECDC are useful for assessing temporal trends at the European level and within individual countries; these data may also be used for benchmarking across EU countries. While DDD - although imperfect - are the most widely accepted metric for this purpose, antibiotic packages do not appear suitable for comparisons between countries and may be misleading [14,15]. Indeed, while comparable results were found in France and Belgium when assessing antibiotic consumption based on prescriptions or DDD, using packages would 
have implied that consumption in France was twice as high as in Belgium. Likewise, Slovenia and Sweden had similar consumption if expressed in DDD per 1,000 ipd, but a $42 \%$ difference when using OAP [14].

A dialogue should be initiated at the European level with manufacturers and regulatory authorities regarding the size and harmonisation of antibiotic packages. It is conventionally recognised that the drug dosage per package should correspond to the most common indication for adults. In that case, the average number of packages delivered per prescription should be close to 1 , as is the case in Belgium, where packages appear to be a good surrogate for prescriptions $[8,16,17]$. This is not the case in France or Slovenia [14], where packages often contain less active substance than in Belgium or Sweden. The result is that the international comparisons are distorted when packages are taken as a surrogate for prescriptions and antibiotic use. Since there may be different dosages and duration of therapy prescribed for different indications, it is unrealistic to expect that packages accurately reflect prescriptions, unless this is adjusted for prescribed daily doses. Using packages as a metric for exposure to antibiotics may however be useful for examining trends in consumption in specific subgroups. For example, since the daily dose ascribed to each active substance is based on adult dosages, antibiotic consumption in children is underestimated. For that specific age group, examining antibiotic consumption of paediatric packages could be of interest.

Monitoring antibiotic use is a global priority to inform public health policies. Recently, the Drive-AB group proposed a set of indicators, especially for the outpatient setting [18], including, besides DDD, prescriptions and treatment courses per defined population. The US Centers for Diseases Control and Prevention advocate using prescriptions [19]. Development of valid indicators for outpatient antibiotic use allowing country comparisons across the $\mathrm{EU}$ is a real challenge [20]. Currently, antibiotic consumption indicators in EU countries are mostly derived from sales data. Because they can be linked to prescriptions and patients, antibiotic consumption indicators using reimbursement data should be developed and used whenever possible. However, this may not be suitable for all EU countries; for example in Spain, some antibiotics are not recorded in the reimbursement database, resulting in underestimation of the actual consumption [6].

\section{Conclusions}

Currently, the use of packages in order to measure the antibiotic consumption appears unsuitable. It could mislead the public to believe that all packages are equal, irrespective of content (dose, number of tablets, etc.). Unless harmonisation of packages is achieved across EU countries, using the number of packages as a measure of antibiotic exposure should therefore be limited to providing additional perspectives in order to explain specific evolutions.
In conclusion, we advocate not using OAP as a surrogate for prescriptions for benchmarking antibiotic consumption across Europe until package content or prescribed daily doses have been harmonised.

\section{Conflict of interest}

None declared.

Authors' contributions

LW performed data analyses. All authors contributed to the article and approved the final version.

\section{References}

1. ATC/DDD Index. 2017. Oslo: World Health Organization Collaborating Centre for Drug Statistics Methodology; December 2016. Available from: https://www.whocc.no/ atc_ddd_index/

2. European Centre for Disease Prevention and Control (ECDC). Summary of the latest data on antibiotic consumption in the European Union. November 2014. Stockholm: ECDC; 2014. Available from: https://ecdc.europa.eu/sites/portal/files/ documents/antibiotics-consumption-EU-data-2014.pdf

3. European Centre for Disease Prevention and Control (ECDC). Summary of the latest data on antibiotic consumption in the European Union. November 2015. Stockholm: ECDC; 2015. Available from: https://ecdc.europa.eu/sites/portal/files/ documents/antibiotics-consumption-EU-data-2015.pdf

4. European Centre for Disease Prevention and Control (ECDC). Summary of the latest data on antibiotic consumption in the European Union. ESAC-Net surveillance data, November 2016. Stockholm: ECDC; 2016. Available from: https://ecdc.europa. eu/sites/portal/files/documents/antibiotics-ESAC-Net \%20 Summary\%202016_0.pdf

5. Davey P, Ferech M, Ansari F, Muller A, Goossens HESAC Project Group. Outpatient antibiotic use in the four administrations of the UK: cross-sectional and longitudinal analysis. J Antimicrob Chemother. 2008;62(6):1441-7. https://doi.org/10.1093/jac/ dkn386 PMID: 18786937

6. Campos J, Ferech M, Lázaro E, de Abajo F, Oteo J, Stephens $P$, et al. Surveillance of outpatient antibiotic consumption in Spain according to sales data and reimbursement data. J Antimicrob Chemother. 2007;60(3):698-701. https://doi. org/10.1093/jac/dkm248 PMID: 17616551

7. Sabuncu E, David J, Bernède-Bauduin $C$, Pépin $S$, Leroy $M$, Boëlle P-Y, et al. Significant reduction of antibiotic use in the community after a nationwide campaign in France, 2002-2007. PLoS Med. 2009;6(6):e1000084. https://doi.org/10.1371/ journal.pmed.1000084 PMID: 19492093

8. Coenen S, Gielen B, Blommaert A, Beutels P, Hens N, Goossens $\mathrm{H}$. Appropriate international measures for outpatient antibiotic prescribing and consumption: recommendations from a national data comparison of different measures. I Antimicrob Chemother. 2014;69(2):529-34. https://doi.org/10.1093/jac/ dkt385 PMID: 24084641

9. Institut national de la statistique et des études économiques (Insee). Population totale au 1er janvier - France métropolitaine. [Total population on 1 January - mainland France]. Paris: Insee. [Accessed: 26 Sep 2017]. French. Available from: https://www.insee.fr/fr/statistiques/ serie/000067670

10. Base de données publique des médicaments. [Public drug database]. Paris: Ministère des solidarités et de la santé. [Accessed: 26 Sep 2017]. 2017. French. Available from: http:// base-donnees-publique.medicaments.gouv.fr/

11. Centre Belge d'Information Pharmacothérapeutique (CBIP). Répertoire commenté des Médicaments. [Commented directory of drugs]. Gent: CBIP; 2017. French. Available from: http:// www.cbip.be/fr/chapters

12. Belgian Antibiotic Policy Coordination Committee (BAPCOC). Guide Belge des traitements anti-infectieux en pratique ambulatoire. [Belgian guide to anti-infective treatments in outpatient practice]. Brussels: BAPCOC; 2012. French. Available from: http://www.cbip.be/legacy_assets/ antibioticagids-fr.pdf

13. Société de pathologie infectieuse de langue française (Spilf), Agence française de sécurité sanitaire des produits de santé 
(AFSSAPS), Société de pneumologie de langue française (SPLF). Mise au point. Antibiothérapie par voie générale dans les infections respiratoires basses de l'adulte. [Focus. General antibiotic therapy in lower respiratory tract infections in adults]. Saint-Denis Cedex: AFSSAPS; 2010. French. Available from: http://www.infectiologie.com/UserFiles/File/medias/ documents/consensus/2010-infVRB-spilf-afssaps.pdf

14. Cižman M. Measurement units for antibiotic consumption in outpatients. J Antimicrob Chemother. 2014;69(10):2877-8. https://doi.org/10.1093/jac/dku194 PMID: 24898018

15. Coenen S, Bruyndonckx R, Hens N, Aerts M, Goossens H. Comment on: Measurement units for antibiotic consumption in outpatients. J Antimicrob Chemother. 2014;69(12):3445-6. https://doi.org/10.1093/jac/dku292 PMID: 25204344

16. Bruyndonckx R, Hens N, Aerts M, Goossens H, Molenberghs $\mathrm{G}$, Coenen $\mathrm{S}$. Measuring trends of outpatient antibiotic use in Europe: jointly modelling longitudinal data in defined daily doses and packages. J Antimicrob Chemother. 2014;69(7):19816. https://doi.org/10.1093/jac/dkuo63 PMID: 24623832

17. Bruyndonckx R, Hens N, Aerts M, Goossens H, Cortiñas Abrahantes J, Coenen S. Exploring the association between resistance and outpatient antibiotic use expressed as DDDs or packages. J Antimicrob Chemother. 2015;70(4):1241-4. https:// doi.org/10.1093/jac/dku525 PMID: 25585511

18. DRIVE AB WP-1A: Quality indicators and quantity metrics of antibiotic use. [Accessed: 26 Sep 2017]. Available from: http:// drive-ab.eu/wp-content/uploads/2014/09/WP1A_Final-QMsQIs_final.pdf

19. Centers for Disease Control and Prevention (CDC). Antibiotic use in the United States, 2017: progress and opportunities. Atlanta: CDC; 2017. Available from: https://www.cdc.gov/ antibiotic-use/stewardship-report/pdf/stewardship-report.pdf

20. Coenen S, Ferech M, Haaijer-Ruskamp FM, Butler CC, Vander Stichele RH, Verheij TJM, et al. European Surveillance of Antimicrobial Consumption (ESAC): quality indicators for outpatient antibiotic use in Europe. Qual Saf Health Care. 2007;16(6):440-5. https://doi.org/10.1136/qshc.2006.021121 PMID: 18055888

\section{License and copyright}

This is an open-access article distributed under the terms of the Creative Commons Attribution (CC BY 4.0) Licence. You may share and adapt the material, but must give appropriate credit to the source, provide a link to the licence, and indicate if changes were made.

This article is copyright of the authors, 2017. 